\title{
Polymorphisms of Genes Related to Phase-II Metabolism and the Resistance of Clopidogrel
}

Abdullah Alkattan ${ }^{1 *}$, Ahmed Alkhalifah ${ }^{2}$, Eman Alsalameen ${ }^{3}$, Fatimah Alghanim ${ }^{4}$, and Nashwa Radwan ${ }^{5,6}$

${ }^{1}$ General Directorate of Medical Consultations, Ministry of Heath, Riyadh, Saudi Arabia.

${ }^{2}$ Fresenius Kabi, Alhaya Medical Company, Riyadh, Saudi Arabia.

${ }^{3}$ Department of Pharmacy, King Khalid University Hospital, Medical City King Saud University, Riyadh, Saudi Arabia.

${ }^{4}$ Faculty of Medicine, Imam Abdulrahman bin Faisal University.

${ }^{5}$ Department of Public Health and Community Medicine, Faculty of Medicine, Tanta University, Tanta, Egypt.

${ }^{6}$ Department of Research, Assisting Deputyship for Primary Health Care, Ministry of Heath, Riyadh, Saudi Arabia.

*Correspondence to

Abdullah Alkattan

abdullahalkattan@gmail.com 


\begin{abstract}
Clopidogrel is one of the thienopyridine antiplatelet drugs commonly used as a prophylactic medication to prevent coagulation in vessels and cardiovascular events. The molecule of clopidogrel is metabolized in the liver via phase-I and phase-II metabolism pathways. The sulfenic acid clopidogrel metabolite undergoes phase-II metabolism through conjugation with glutathione by the glutathione-s-transferase $(G S T)$ to form a glutathione conjugate of clopidogrel (inactive metabolite). A glutaredoxin enzyme removes the glutathione conjugated with clopidogrel to form cis-thiol-clopidogrel. This review focused on the polymorphisms of genes related to phase-II metabolism during the clopidogrel bioactivation process. Overall, no well-controlled studies were done about the relationship between the clopidogrel bioactivation process and genes related to phase-II metabolism's enzymes. Nevertheless, some polymorphisms of G6PD, GCLC, GCLM, $G S S, G S T, G S R, H K$, and GLRX genes could be responsible for clopidogrel resistance due to low glutathione conjugate or glutaredoxin plasma levels. Studies needed to be concerned with the relationship between clopidogrel resistance and phase-II metabolism issues in the near future.
\end{abstract}

\title{
Keywords
}

Polymorphism; genes; phase-II metabolism; glutathione; clopidogrel resistance 


\section{Introduction}

Thienopyridine antiplatelets are a group of drugs that are irreversibly blocking one of the adenosine diphosphate (ADP) receptors called P2Y12 receptors. Clopidogrel is one of the thienopyridines antiplatelet drugs that are commonly used as a prophylactic medication in order to prevent coagulation in vessels and cardiovascular events.[1]

The molecule of clopidogrel is metabolized in the liver via phase-I and Phase-II metabolism pathways. In the phase-I metabolism, 85\% of absorbed clopidogrel hydrolyzed via carboxylesterase-1 (CES-1) enzyme to be converted to clopidogrel carboxylic acid (inactive metabolite). The remaining absorbed clopidogrel was oxidized via cytochrome P450 1A2 (CYP1A2), CYP2C19, and CYP2B6 enzymes to convert to 2oxo-clopidogrel. The inactive metabolite (2-oxo-clopidogrel) is either further metabolized in phase-I metabolism via CYP2C19, CYP2C9, CYP3A4, and CYP2B6 enzymes to converted to sulfenic acid clopidogrel (inactive metabolite), or converted to cis-thiol-clopidogrel, which is described as the active metabolite of the prodrug clopidogrel.[2]

The sulfenic acid clopidogrel metabolite undergoes phase-II metabolism through conjugation with glutathione by the glutathione-s-transferase (GST) to form a glutathione conjugate of clopidogrel (inactive metabolite).[3] A glutaredoxin enzyme removes the glutathione conjugated with clopidogrel to form cis-thiol-clopidogrel.[4]

Clopidogrel's antiplatelet efficacy depends on some enzymes involved in phase-I and phase-II metabolism. Therefore, some polymorphism of genes related to these metabolic enzymes could affect the bioactivation process of clopidogrel.

This review will focus on the polymorphisms of genes related to phase-II metabolism during the clopidogrel bioactivation process. 


\section{Polymorphism of glucose-6-phosphate dehydrogenase (G6PD) gene}

\subsection{Overview}

Glucose-6-phosphate dehydrogenase (G6PD) is an enzyme responsible for converting about $9 \%$ of glucose-6-phosphate into 6-phosphate gluconate with the help of the oxidative form of nicotinamide adenine dinucleotide phosphate (NADP+) which reduced then by adding hydrogen ion by G6PD enzyme to form NADPH.[5]

NADPH is a cofactor that helps some enzymes include 3-hydroxy-3-methyl-glutarylCoenzyme-A reductase (HMG-CoA reductase) enzyme (to form mevalonic acid) and glutathione reductase (GR) enzyme (to form two glutathione molecules), thus, the G6PD enzyme is essential for keeping normal levels of glutathione molecules in blood plasma (see figure.1).[6-7]

\subsection{Expression}

G6PD enzyme is encoded by the G6PD gene found in chromosome Xq28 and has 13 exons. The Expression of the G6PD gene takes place mainly at testes, granulocytes, and bone marrow cells.[8]

\subsection{Variation}

The wild-types' alleles of the G6PD gene include G6PD $A+$ and G6PD B, however, there are more than 400 different polymorphisms found globally related to the G6PD gene, but the most common mutations' alleles found are G6PD San Diego, G6PD Chatham, G6PD Mediterranean, G6PD Aures, G6PD Canton, G6PD A- and G6PD Hektoen (see table.1).[9-10]

G6PD Chatham allele is caused by a single nucleotide polymorphism of the G6PD gene at sequence number 1003 , which guanine replaced with adenine, thus affecting the transcription of the G6PD gene into mRNA and therefore losing more than $90 \%$ of the regular activity of the G6PD enzyme. G6PD Chatham allele is less frequently found than G6PD Mediterranean and G6PD A- alleles.[11]

G6PD Mediterranean allele is also caused by a single nucleotide polymorphism of the $G 6 P D$ gene, however, it is caused by replacing the cytosine nucleotide at sequence number 563 with thymine. Like the G6PD Chatham allele, the G6PD Mediterranean allele leads to the severe reduction of the G6PD enzyme activity, less than 10\% of G6PD protein produced from the G6PD Mediterranean allele is described as an active enzyme. G6PD Mediterranean allele is commonly found in Mediterranean European countries, including Italy and Grease, and shared in the Middle East countries, including Saudi Arabia, Egypt and Iran, and Indian people.[12]

G6PD Aures allele is caused by mutation at sequence number 143 of the G6PD gene, which thymine nucleotide changed to cytosine. G6PD Aures allele's phenotype is the G6PD enzyme deficiency, but unlike G6PD Chathan and G6PD Mediterranean alleles, the G6PD Aures allele causes a mild deficiency of G6PD enzyme with up to $60 \%$ of G6PD enzyme described as active. 
G6PD Aures allele was first discovered in a child from Algeria in 1993, then it found that many Algerian people have G6PD Aures allele, but because of causing an only mild type of G6PD enzyme deficiency, it did not lead to severe or even obvious hemolytic anemia or other issues. G6PD Aures allele also had been discovered in other countries including Saudi Arabia, Tunisia, Jordan, Kuwait, and the United Arab Emirates.[13]

G6PD A- allele is the most common allele (after G6PD Mediterranean allele) found globally, but most frequently in Africa, the Middle East, and South Europe. Like G6PD Aures, the G6PD A- allele results in a mild deficiency of the G6PD enzyme (the activity of the G6PD enzyme is up to 60\%). However, the G6PD A- allele is caused by a mutation at sequence number 202 of the G6PD gene, in which guanine nucleotide is replaced with adenine.[14]

G6PD Hektoen allele is the least common variant of the G6PD gene caused by a single nucleotide polymorphism that makes one change on the G6PD protein, a histidine amino acid replaced with tyrosine, but it is not well known at which amino acid position this replacement takes place. This change makes the G6PD protein have extra (up to 400\%) enzymatic activity than the normal G6PD protein encoded via the G6PD wild-types' alleles (4 folds more enzymatic activity than normal G6PD protein).[15]

\subsection{Effect of G6PD gene's variations on clopidogrel antiplatelets activity}

Patients with severe G6PD enzyme deficiency (because of having either G6PD Chatham or Mediterranean alleles) may lead to a noticeable reduction of glutathione (GSH) level in blood plasma. Since clopidogrel drug needs GSH in order to be activated, clopidogrel could not be activated entirely in patients with severe G6PD enzyme deficiency (see figure.2).[16] Overall, no well-controlled studies were done about the antiplatelet efficacy of clopidogrel on patients with severe G6PD enzyme deficiency. 


\section{Polymorphism of glutamate-cysteine ligase catalytic and modifier subunits (GCLC and $G C L M$ ) genes}

\subsection{Overview}

Glutathione is a molecule biosynthesized from a combination of glutamate, cysteine, and glycine amino acids, and these three amino acids are combined together by the activity of two enzymes in two steps. The first step is combining glutamate with cysteine and ATP molecule via glutamate-cysteine ligase enzyme, this binding leads to the formation of $\gamma$ glutamyl cysteine (see figure.3). The second step in glutathione biosynthesis is the binding of $\gamma$-glutamyl cysteine with a glycine amino acid and ATP molecule by the activity of glutathione synthase enzyme to produce glutathione.[17] The glutamatecysteine ligase composed of two subunits, including glutamate-cysteine ligase catalytic subunit (GCLC) and glutamate-cysteine ligase modifier subunit (GCLM), and each subunit is encoded by different genes found at different chromosomes in the human genome.[18]

\subsection{Expression}

Glutamate-cysteine ligase catalytic subunit (GCLC) is encoded via the GCLC gene. GCLC gene located in chromosome 6p12.1, which encoded mainly in bone marrow cells, and many studies showed that GCLC gene knockout or presence of some polymorphisms could reduce glutathione plasma level cause hemolytic anemia. On the other hand, glutamate-cysteine ligase modifier subunit (GCLM) is encoded by the GCLM gene found in chromosome 1p22.1.[19]

\subsection{Variations}

\subsubsection{GCLC Gene Variations}

$G C L C$ gene variants caused by single nucleotide polymorphisms and these variants include:

1- $r s 761142$ GCLC allele (rs = reference single nucleotide polymorphism), which thymine replaced with guanine at undetermined sequence on the $G C L C$ gene, results in a reduction of GCLC mRNA expression and glutamate-cysteine ligase enzyme production, therefore, reduction of glutathione biosynthesis. The $r$ s 761142 GCLC allele is commonly found in patients infected with the human immunodeficiency virus (HIV) and having acquired immunodeficiency syndrome (AIDS).

Some studies reveal that giving sulfa drugs like sulfamethoxazole antibacterial drug to patients with decrease glutathione synthesis due to the presence of $r s 761142$ GCLC allele could lead to severe allergy and also may cause hemolytic anemia.[20]

2- GCLC - $129 T>C$ allele is another single nucleotide polymorphism of the $G C L C$ gene caused by the replacement of thymine nucleotide by cytosine at the regulatory region 129 sequence of the $G C L C$ gene. Like $G C L C-588 C>T$ allele, $G C L C-129 T>C$ allele leads to a reduction of glutathione plasma level because of low expression of glutathione- 
cysteine ligase enzyme and also may increase the risk of having ischemic heart disease in patients with $129 T>C$ allele.[21]

\subsubsection{GCLM gene variations}

One studied polymorphism of the GCLM gene called GCLM -588C>T allele caused by changing cytosine nucleotide with thymine at the regulatory region the sequence number -588 of the $G C L C$ gene. The presence of $G C L C-588 C>T$ allele causes low expression of glutamate-cysteine ligase enzyme, resulting in lower glutathione plasma levels than wildtype $G C L C$ allele.

A previous study in Kazakhstan reveals that patients carrying $G C L C-588 C>T$ allele have a higher chance of developing ischemic heart disease, which could mainly be caused by the chronic highly oxidative stress condition that resulted from low glutathione production.[22]

\subsection{Effect of GCLC and GCLM genes' variations on clopidogrel antiplatelets activity} Low glutathione plasma level caused by rs761142 GCLC, GCLM -588C>T or GCLC $129 T>C$ alleles could affect the bioactivation process of clopidogrel prodrug, which makes this drug unable to inhibit the platelets aggregation perfectly, thus leading to severe consequences in patients with a high risk of blood coagulation. So far, no wellcontrolled researches done about the relationship between GCLC variants and clopidogrel antiplatelet efficacy. 


\section{Polymorphism of Glutathione Synthase gene}

\subsection{Overview}

Glutathione synthase (GSS) gene is the source of glutathione synthase enzyme, which is an essential enzyme in the biosynthesis of glutathione that acts as a cofactor for antioxidant enzymes (see figure.4).[23]

\subsection{Expression}

GSS gene is located in chromosome 20q11.22 and has 13 exons.[24]

\subsection{Variations}

Polymorphic alleles of glutathione synthase include:

\subsubsection{GSS alleles causing a mild type of glutathione synthase enzyme deficiency} (GSS activity >20\%):

- GSS 656A>G allele.[24]

\subsubsection{GSS alleles causing the moderate type of glutathione synthase enzyme deficiency (GSS activity 10-20\%):}

- GSS 77C>A allele.[25]

- $G S S$ 491G $>A$ allele.[26]

\subsubsection{GSS alleles causing severe type of glutathione synthase enzyme deficiency (GSS activity <10\%):}

- GSS 374G $>A$ allele.[26]

- GSS 563T>C allele.[25]

- GSS 808T>C allele.[27]

- GSS 809A>G allele.[27]

- GSS 847C>T allele.[26]

- GSS $1034 A>G$ allele.[25]

\subsection{Effect of GSS gene variations on clopidogrel antiplatelet activity}

Glutathione is needed for the conjugation process during clopidogrel activation. Thus low glutathione plasma level caused by different polymorphisms of glutathione synthase could decrease the antiplatelet efficacy of clopidogrel. Well-controlled trials done about the relationship between $G S S$ variants and clopidogrel antiplatelet efficacy were not found. 


\section{Polymorphism of GST genes}

\subsection{Overview}

Glutathione-s-transferase (GST) is a protein enzyme responsible for the glutathione conjugation process during phase-II metabolism (see figure.5).

Glutathione conjugation is an important mechanism to reduce oxidative stress, detoxify and facilitate excretion of many toxins/drugs, and be necessary to activate some prodrugs.[28]

There are 13 types of GST enzyme, however, only 5 GST enzyme gene families in humans are essential because of different polymorphisms. These essential GST genes include:

- GSTM (mu)

-GSTP (pi)

-GSTT (theta)

- GSTA (alpha)

-GSTO (omega)

Until today, polymorphisms confirmed for GSTM, GSTP, GSTT, GSTA, and GSTO genes are shown in table.2.

\subsection{Expression}

Because different GST enzymes encoded from 5 different genes, we will discuss the details of every gene briefly.

\section{1- Glutathione-s-transferase mu (GSTM) gene}

GSTM enzyme is encoded by the GSTM gene, located in chromosome 1p3.3, and has eight exons. GSTM gene mainly encoded in liver cells.[29]

\section{2- Glutathione-s-transferase pi (GSTP) gene}

GSTP enzyme is encoded by the GSTP gene, located in chromosome 11q13.3, and has seven exons. GSTP gene is mainly encoded in bronchial epithelial cells, colorectal cells, and B lymphocytes.[30]

\section{3- Glutathione-s-transferase theta (GSTT) gene}

GSTT enzyme is encoded by the GSTT gene, located in chromosome 22q11.23, and has five exons. GSTT gene is mainly encoded in prostate, lung, and thyroid cells.[31]

\section{4- Glutathione-s-transferase alpha (GSTA) gene}

GSTA enzyme is encoded by the GSTA gene, which is located in chromosome 6p12.2 and has seven exons. GSTA gene mainly encoded in the adrenal gland, kidney, liver, and testis.[32] 


\section{5- Glutathione-s-transferase omega (GSTO) gene}

GSTO enzyme is encoded by the GSTO gene, located in chromosome 10q25.1, and has six exons. GSTO gene is mainly encoded in monocytes, B lymphocytes, liver, bronchi, uterus, heart, and bone marrow cells.[33]

\subsection{Variations}

\section{1) Variations of the GSTM gene}

The most common polymorphic allele for the GSTM gene is called GSTMI*O (null), in which the gene is deleted.

Therefore, any person with GSTMI*0 allele will probably have GST enzyme deficiency, and the glutathione conjugation mechanism will also be affected.

$G S T M * 0$ allele is frequently found among Asians ( $\approx 58 \%)$, Caucasians $(\approx 43 \%)$, and Africans $(\approx 21 \%)$.[34-35]

\section{2) Variations of GSTP gene}

There are three common variant alleles for the GSTP gene: GSTP ${ }^{*} B, G S T P 1 * C$, and $G S T P 1 * D$. GSTP $1 * B$ allele is one of the most common $G S T$ genes' alleles among different populations, and causing a reduction of GSTP enzyme activity in about $33 \%$ of Africans, $30 \%$ of Caucasians, and $21 \%$ of Asians.

$G S T P 1 * C$ allele is caused by a single nucleotide polymorphism that causing a change of the amino acid number 114 of the GSTP enzyme, which alanine amino acid replaced with valine. However, this change in the amino acid of GSTP protein did not show any reduction of the enzyme's activity. Therefore, the $G S T P 1 * C$ allele expresses almost GSTP protein with normal enzyme activity. GSTP $1 * D$ allele is the least common mutation found and no well-controlled study about whether it affects GST enzyme activity or not.[36]

\section{3) Variations of the GSTT gene}

Like the GSTM gene, the GSTT gene has one common variant allele (GSTT1*0) and probably will have GST enzyme deficiency, and the glutathione conjugation mechanism will also be affected. $G S T T 1 * 0$ allele is frequently existing among more than $50 \%$ of Asians, more than $30 \%$ of Africans, and about $20 \%$ of Caucasians.[37]

\section{4) Variations of the GSTA gene}

It found that the GSTA gene could be affected frequently by one mutation called the $G S T A 1 * B$ allele. This polymorphism reduces GSTA mRNA transcription, which leads to a decrease in GSTA enzyme activity. Some previous studies revealed that $G S T A 1 * B$ allele was found among $40 \%$ of Caucasians and 10\% of Asians.[38] 


\section{5) Variations of GSTO gene}

GSTO1 and GSTO2 are isoenzymes that are encoded from different genes. However, both GSTO1 and GSTO2 genes are found in the same chromosome and near to each other.

GSTO1 gene could be affected by only one mutation called $G S T O 1 * B$ allele. On the other hand, the GSTO2 gene was affected by two polymorphisms, including GSTO2*B and $G S T O 2 * C$ alleles.

$G S T O 1 * B$ allele resulted from deleting only one amino acid (glutamic acid) at amino acid number 155 of the GSTO1 protein enzyme. This mutation's phenotype is the inability of the GSTO1 enzyme to work, which causes GSTO1 enzyme deficiency among people carrying the $G S T O 1 * B$ allele.

$G S T O 2 * B$ (also called GSTO2*N142D) allele is a mutation caused by the replacement of asparagine amino acid with aspartic acid at the amino acid position number 142 of the GSTO2 protein enzyme. GSTO2*B allele is commonly found in Africans, especially South Africans ethnic groups include the Ovambos population.[39]

\subsection{Effect of $G S T$ genes' variations on clopidogrel antiplatelet activity}

Because some studies showed that glutathione conjugates with clopidogrel during the bioactivation process via GST enzymes, it indicates that the mutation of GST genes' polymorphisms could decrease the antiplatelet activity of clopidogrel. However, no wellcontrolled researches done about the relationship between $G S T$ variants and clopidogrel antiplatelet efficacy. 


\section{Polymorphism of Glutathione Disulfide Reductase gene}

\subsection{Overview}

Glutathione disulfide reductase (GSR) or also called glutathione reductase (GR), is an enzyme that responsible for breaching the disulfide bond from the oxidized form of glutathione to produce two molecules of reduced glutathione (see figure.6).[40] The activity of the GSR enzyme depends on NADPH and FAD (Flavin adenine dinucleotide) molecules that derived from nicotinamide (vitamin B3) and riboflavin (vitamin B2), respectively, therefore, the GSR enzyme activity could be lower if there is a deficiency of nicotinamide or riboflavin.[41]

\subsection{Expression}

GSR enzyme is encoded from the GSR gene, located in chromosome 8p12, and has 13 exons.[42]

\subsection{Variations}

The genetic variations of the GSR gene are not commonly studied, and only a few researches published about GSR polymorphisms. There are two well-studied alleles of the $G S R$ gene include:

- rs2251780 allele.

-rs3779647 allele.[43]

\subsection{Effect of GSR genes' variations on clopidogrel antiplatelet activity}

Mutations of the glutathione reductase gene could lead to glutathione deficiency, therefore, it could reduce the clopidogrel's bioactivation mechanism. We did not find any well-controlled study about the relationship between $G S R$ variants and clopidogrel antiplatelet efficacy. 


\section{Polymorphism of Hexokinase genes}

\subsection{Overview}

Hexokinase is a group of enzymes responsible for the first step of the metabolism of hexose monosaccharide molecules, mainly glucose, fructose, and mannose.[44] The hexokinase mechanism is by adding a phosphate group at the sixth carbon of hexose monosaccharides. Therefore, hexokinase convert glucose, fructose, and mannose into glucose-6-phosphate, fructose-6-phosphate, and mannose-6-phosphate respectively (see figure.7).[45]

Hexokinase enzymes are essential in reducing oxidative stress via activating glucose-6phosphate dehydrogenase (G6PD) enzyme, which is vital in the activation of glutathione reductase enzyme that resulted in the production of two glutathione molecules.[46]

\subsection{Types of hexokinase enzymes}

There are four different types of hexokinase encoded from four different genes located in different chromosomes (see Table 3). These four types of hexokinase include:

-Hexokinase-1.

-Hexokinase-2.

-Hexokinase-3.

-Glucokinase (also called hexokinase-4).[47]

\subsubsection{Hexokinase-1}

The hexokinase- 1 enzyme is encoded from the $H K-1$ gene located in chromosome $10 \mathrm{q} 22.1$ and consists of 25 exons. The expression of the $H K-1$ gene takes place mainly in bone marrow cells and monocytes.[48]

\subsubsection{Hexokinase-1 gene variations}

There are five recognized polymorphic alleles of the $H K-1$ gene include:

\section{$-H K-1$ 1216A>G allele}

It is a rare allele caused by a single nucleotide polymorphism at the base pair number 1205 of the $H K-1$ gene, in which adenine nucleotide is replaced with guanine. $H K-1$ $1216 A>G$ allele probably results in hexokinase deficiency and may cause brain or vision disorders.

\section{$-H K-11334 C>T$ allele}

This allele is a well-studied variant of the $H K-1$ gene caused by the replacement of cytosine nucleotide with thymine at the base pair number 1334 and the translation of methionine instead of threonine at the amino acid number 445 of the hexokinase- 1 protein.

Like $H K-1 \quad 1216 A>G$ allele, $H K-1 \quad 1334 C>T$ allele causes hexokinase enzyme deficiency and may lead to visual abnormalities and defects in the central nervous system. 


\section{$-H K-1$ 1667T>C allele}

One of the oldest mutations recognized in the $H K-1$ gene is the $H K-11667 T>C$ allele, resulting in the translation of serine amino acid instead of leucine.

A previous study revealed that some patients with hexokinase enzyme deficiency having $H K-11667 T>C$ allele in their genetic makeup. Therefore, the presence of $H K-1$ $1667 T>C$ allele in humans could lead to a defect in the transcription of hexokinase-1 mRNA or/and a defect in the translation of the fully active form of hexokinase- 1 enzyme, which result in hexokinase enzyme deficiency.

\section{$-H K-12539 G>A$ allele}

An allele in the $H K-1$ gene could cause a severe condition of hexokinase deficiency. This allele called $H K-12539 G>A$ and resulted from a rare mutation at the base pair number 2539 in the $H K-1$ gene, in which a guanine nucleotide replaced with adenine, thus makes changes on the hexokinase enzyme's amino acids sequence at the position number 847 , which a lysine amino acid is translated from $H K-1$ 2539G $>A$ allele instead of glutamine.

People with $H K-12539 G>A$ have a high risk of having retinitis pigmentosa, a rare disorder caused by mutation of many genes, including the $H K-1$ gene.

\section{$-H K-19712 G>C$ allele}

One of the most frequent mutations of the $H K-1$ gene among Gypsies people in Spain and Slovakia is caused by $H K-19712 G>C$ allele.

A Spanish group of researchers reveals that people carrying $H K-19712 G>C$ allele could have a higher risk of a hereditary motor and sensory neuropathy (HMSN disorder called Charcot Marie Tooth (CMT) disease, which affects the peripheral nervous system. Also, the study showed that $H K-19712 G>C$ allele is very commonly presented in the Romani ethnic group (Gypsies people).

A Slovakian study also confirmed that the $H K-19712 G>C$ allele was found more frequent in Romani people and showed a correlation between the incidence of CMT disease and the presenting of $H K-19712 G>C$ allele.[49-50-51]

\subsubsection{Hexokinase-2}

Unlike hexokinase-1, the hexokinase-2 enzyme is mainly encoded in skeletal muscle and cardiac muscle, and its expression is induced by insulin. Hexokinase- 2 encoded via $H K-2$ gene located in chromosome number 2 at band p13 and has 18 exons.[52] 


\subsubsection{Hexokinase-2 gene variations}

$H K-2$ gene found to be affected mainly by four types of missense mutations include:

-HK-2 mRNA codon $142 Q>H$ mutation allele.[53]

-HK-2 mRNA codon $148 \mathrm{~L}>F$ mutation allele.

-HK-2 mRNA codon $497 R>Q$ mutation allele.[54]

-HK-2 $m R N A$ codon $844 R>K$ mutation allele.[55]

All the above variations' alleles of the $H K-2$ gene are lead to hexokinase deficiency in skeletal muscles, and some studies are done about $H K-2$ genes' mutations and their correlation with the incidence of type-2 diabetes mellitus (T2DM).

A previous study revealed that changes in hexokinase- 2 enzyme activity could cause metabolic disorders, including diabetes mellitus. The role of hexokinase- 2 deficiency in causing diabetes or metabolic disorder is by reducing the metabolism of glucose and other hexose monosaccharides, thus decreasing the synthesis of glycogen in the skeletal muscles, which contribute to insulin-resistant and affecting the metabolism of carbohydrates, proteins, and lipids.[56] On the other hand, a high level of glucose-6phosphate (because of G6PD deficiency) could inhibit the activity of the hexokinase-2 enzyme, which also could cause diabetes mellitus (see figure.8).

Hexokinase-2 deficiency could also lead to increase muscle damage due to the reduction of glutathione in muscle cells, which could also lead to chronic inflammatory status and fatigue.[57]

\subsubsection{Hexokinase-3}

This enzyme (hexokinase-3) is the third type of hexokinase enzyme. The hexokinase- 3 enzyme encoded by $H K-3$ gene located at the chromosome 5 band 35.3 and highly encoded in liver, kidney, and lung tissues.[58]

\subsubsection{Hexokinase-3 gene variations}

There are mainly two variations of the $H K-3$ gene caused by two mutations include:

-HK-3 rs691141 allele.

$-H K-3$ rs2278493 allele.

These two alleles result from a single nucleotide mutation of the $H K-3$ gene, in which cytosine nucleotide changed with thymine (HK-3 rs691141 allele) and guanine replaced with adenine ( $H K-3$ rs 2278493 allele). However, it is not well known for the mutations' positions of these two alleles.

Many studies are done about $H K-3$ gene mutations ( $H K-3$ rs691141 and HK-3 rs2278493 alleles) and their correlation with age at menopause or/and premature ovarian failure. Some of these studies discovered that two alleles of $H K-3$ gene associated with early menopause and premature ovarian failure.[59] 


\subsubsection{Hexokinase-4 (Glucokinase):}

Hexokinase type 4 enzyme (commonly known as glucokinase) is encoded via the $G C K$ gene found at the chromosome 7 band p13 and has 12 exons. The expression of the $G C K$ gene mainly takes place in hepatic and pancreatic beta cells.[60]

Unlike the first three types of hexokinases (hexokinase 1,2 and 3), the glucokinase enzyme is responsible for glucose metabolism only (glucokinase is highly sensitive for glucose but is very less sensitive to fructose). Besides, glucokinase is not inhibited by glucose-6-phosphate molecules.[61]

\subsubsection{Hexokinase-4 gene variations}

$G C K$ gene is one of the commonly well-studied genes, since its mutation could frequently lead to metabolic disorders, especially MODY-2 (maturity-onset diabetes of the young type 2) or GCK-MODY, which is a form of mild type-2 diabetes in children.[62] There are more than 150 GCK gene mutations, and many of these variants are causing glucokinase enzyme deficiency and may lead to pathogenic disorders include MODY, hypertension, or cardiovascular diseases.[63] The following GCK gene's mutations are an example of some missense polymorphisms that lead to various disorders:

\section{-GCK 391T>C allele}

A mutation of $G C K$ causes this allele at the base pair number 391, which thymine nucleotide replaced with cytosine. This replacement resulted in a change of translated amino acid serine into proline at sequence number 131 of the glucokinase enzyme protein. $G C K 391 T>C$ allele is positively linked to hyperglycemic status and increase the risk of diabetes incidence as a result of glucokinase enzyme deficiency and metabolic disorders.[64]

\section{$-G C K 556 C>T$ allele}

The replacement of cytosine nucleotide to thymine at the base pair number 556 of the $G C K$ gene resulted in a missense mutation, leading to issues in the transcription and the translation process of the $G C K$ gene glucokinase enzyme deficiency. This single nucleotide polymorphism is related to the incidence of type-2 MODY disease.[65]

\section{$-G C K$ 781G $>A$ allele}

Many studies revealed that when guanine is replaced with adenine at the base pair number 781 of the $G C K$ gene could lead to glucokinase enzyme deficiency and increase the risk of type-2 diabetes.[66]

\section{$-G C K 835 G>C$ allele}

Although few studies are done about $G C K 835 G>C$ allele, it is probably linked with the incidence of type-2 MODY because of glucokinase enzyme deficiency. A single nucleotide polymorphism causes this allele at base-pair number 835, which guanine nucleotide replaced with cytosine. Thus glutamine is translated instead of glutamic acid at the amino acid number 279 of the glucokinase enzyme protein.[67] 


\section{-GCK 895G>C allele}

A single nucleotide polymorphism causes this mutated allele in exon 8 of the $G C K$ gene, which guanine nucleotide replaced with a cytosine at the base pair number 895 . This mutation leads to the translation of arginine instead of glycine at the amino acid number 299 of the glucokinase enzyme protein.[68]

Gestational diabetes mellitus (GDM) disorder in pregnant women is has been linked with $G C K 895 G>C$ allele. A Palestinian study revealed that pregnant women carrying GCK $895 \mathrm{G}>\mathrm{C}$ allele could probably have a higher risk of hyperglycemia (GDM) compared with pregnant women carrying wild-type allele of the $G C K$ gene. On the other hand, a recent study done in Saudi Arabia stated that $G C K$ mutation was not related to GDM in Saudi pregnant women.[69]

\subsection{Effect of HK genes' variations on clopidogrel antiplatelet activity}

A recently published study revealed that reduced GCK mRNA expression because of $G C K$ gene mutation can lead to clopidogrel resistance, which means that clopidogrel could not perfectly inhibit platelet aggregation and may increase the risk of recurrence. cardiovascular events.[70] 


\section{Polymorphism of Glutaredoxin (GLRX) genes}

\subsection{Overview}

Glutaredoxins (GLRXs or Grxs) "also called thioltransferases or thiol-disulfide oxidoreductases" are a group of proteins acting as redox enzymes, which help in the reduction enzymatic reactions of various endogenous and exogenous molecules by breaking down the disulfide bonds either through monothiol or dithiol mechanism, and these reactions need glutathione molecules as cofactors (see figure.9).[71] Glutaredoxins exist in human cells in different forms depending on glutaredoxin amino acids sequence, encoded via different genes at different chromosomes.[72]

\subsubsection{Types of Glutaredoxin (GLRX) enzymes}

Depending on active site differentiation, glutaredoxin classified into two classes (see table.4):

\subsubsection{Class I (Dithiol) glutaredoxin:}

When the active site of the glutaredoxin enzyme composed of cysteine-proline-tyrosinecysteine (CPYC) or cysteine-X amino acid-X amino acid-cysteine (CXXC), it means that the glutaredoxin is described as dithiol glutaredoxin, because it has two cysteine amino acids in its active site.

Class I glutaredoxin is further classified into three subclasses:

\section{- Class Ia glutaredoxin}

It is a glutathione (GSH) dependent enzyme and characterized by small-sized protein, an example of this class is the glutaredoxin-1 enzyme.

\section{- Class Ib glutaredoxin}

Like class Ia, class Ib is a glutathione-dependent enzyme, however, it is known as a larger protein size than class Ia, an example of class Ib is the glutaredoxin-2 enzyme.

\section{- Class Ic glutaredoxin}

Unlike class Ia and class Ib, class Ic glutaredoxin is glutathione independent enzyme and has almost the same structure as glutaredoxin, but its mechanism is thioredoxin*-like activity. An example of class Ic is a glutaredoxin-like protein $(\mathrm{NrdH})$ enzyme.

*Thioredoxin: is an enzyme protein acting like glutaredoxin, but independent of GSH and not related to the glutaredoxin system. 


\subsubsection{Class II (Monothiol) glutaredoxins}

If any glutaredoxin enzyme composed of cysteine-glycine-phenylalanine-serine (CGFS) or cysteine- $\mathrm{X}$ amino acid- $\mathrm{X}$ amino acid- $\mathrm{x}$ amino acid $(\mathrm{CXXX})$ on its active site, therefore it called monothiol (because it has only one cysteine amino acid in its active site) or class II glutaredoxin. In general, all class II glutaredoxins are GSH dependent enzymes. Class II glutaredoxin include:

-Glutaredoxin-3.

-Glutaredoxin-4.

-Glutaredoxin-5.

Because different glutaredoxins encoded via different genes, glutaredoxin could be classified into mainly five types include:

-Glutaredoxin-1.

-Glutaredoxin-2.

-Glutaredoxin-3.

-Glutaredoxin-4 (not found in humans).

-Glutaredoxin-5.[73]

\subsection{Glutaredoxin-1}

Glutaredoxin-1 is a dithiol enzyme encoded by the GLRX-1 gene found at chromosome number 5 band q15, and this gene is encoded mainly in bone marrow, placenta, and bronchial muscle tissues.

This enzyme (glutaredoxin-1) reduces proteins by breaking the disulfide bonds, thus enhancing proteins' folding process and activating important enzymes like ribonucleotide reductase (RRase) enzyme, which is the cornerstone enzyme needed for the synthesis of deoxyribonucleic acid (DNA).

Only one rare variant was discovered for the GLRX-1 gene called rs4767 allele, and not well studied.[74]

\subsection{Glutaredoxin-2}

It is another type of class II glutaredoxin enzyme that has the same catalytic reactions as the glutaredoxin-1. However, it is encoded by a different gene called the GLRX-2 gene found at chromosome number 1 band q31. GLRX-2 gene is encoded in most human tissues but positively detected in testes, and prostate tissues, with significantly lower amounts of $G L R X-2$, detected in the bone marrow.

The glutaredoxin-2 enzyme has an essential role in reducing oxidative stress and the antiapoptotic mechanism in human tissues. Besides, glutaredoxin-2 is described as a redox sensor during oxidative stress conditions within the cells. In normal conditions, glutaredoxin-2 was found as a dimer complex with an iron-sulfur cluster and present as an inactive enzyme. However, during oxidative stress state, iron-sulfur cluster removed, 
and glutaredoxin-2 present as an active monomer enzyme. Because of iron-sulfur clusters binding to glutaredoxin- 2 enzymes, glutaredoxin- 2 inhibits iron overload, thus prevent mitochondrial dysfunction.[75]

A previous study on animals showed that GLRX-2 gene knockout leads to increased apoptosis, tissue damage, and cardiovascular issues.[76]

\section{There are 4 variations of $G L R X-2$ gene, include:}

-GLRX-2 68 cysteine > serine.

-GLRX-2 78 serine >proline.

-GLRX-2 80 cysteine > serine.

-GLRX-2 153 cysteine > serine.

Although the $G L R X-2$ gene's variations are rare, it may cause acute glutaredoxin -2 enzyme deficiency (related to GLRX-2 80 cysteine > serine variant). Besides, it could lead to mitochondrial dysfunction (related to GLRX-2 68 cysteine >serine or GLRX-2 153 cysteine > serine variants) in case of a person having one of the four variants of the GLRX2 gene.[77-78]

\subsection{Glutaredoxin-3}

It is a monothiol glutaredoxin enzyme responsible (along with BOLA2 like protein) for the insertion of Fe-S clusters into proteins in the cell's cytosol and nucleus. Fe-S cluster proteins in cytosol are acting as cofactors for essential enzymes involved in protein synthesis and amino acid metabolism. On the other hand, the iron-sulfur cluster protein in the nucleus acts as cofactors for essential enzymes related to DNA replication and DNA repair.

The glutaredoxin-3 enzyme is encoded by the GLRX-3 gene found at chromosome number 10 band q26. GLRX-3 gene found to be encoded in most human tissues, but more highly encoded in testis, vagina, lymph nodes, appendix, and tonsil.[79]

\section{There are at least four variations of the $G L R X-3$ gene caused by four different mutations, include:}

-GLRX-3 159 cysteine > serine.[80]

-GLRX-3 197-198 tryptophan-proline >aspartic acid-alanine.

-GLRX-3 261 cysteine >serine.

-GLRX-3 299-300 tryptophan-proline >aspartic acid-alanine.

All of these four mutated alleles probably causing glutaredoxin-3 dysfunction and decrease glutaredoxin-3 binding to Fe-S clusters. Therefore, affecting iron-sulfur clusters cofactors' transportation from mitochondria into cytosol and nucleus thus will reduce the enzymatic activities of essential enzymes needed for DNA replication, DNA repair, and protein synthesis.[81] 


\subsection{Glutaredoxin-4}

It is a non-human type of glutaredoxin encoded by the $G L R X-4$ gene (also called $G L R X D)$, which found in various microorganisms, include:

-Buchnera aphidicola (a gram-negative bacteria, which is described as pathogenic in plants).

-Shigella flexneri (a gram-negative bacteria known to cause diarrhea in humans).

-Escherichia coli (a gram-negative bacteria that live in the human gastrointestinal tract as normal flora. However, some strains of Escherichia coli (E.coli) could be pathogenic to humans and may cause cystitis, pyelonephritis, peritonitis, or even sepsis).

-Haemophilus influenza (a gram-negative bacteria known to cause infections in humans, "especially infants and children" includes upper and lower respiratory infections, otitis media, or meningitis).

-Haemophilus ducreyi (a gram-negative bacteria and known to cause sexually transmitted diseases).

-Saccharomyces cerevisiae (a yeast fungus that is rarely known as pathogenic in healthy people but could likely affect immunocompromised patients and may causing systemic fungemia).

-Schizosaccharomyces pombe (a yeast fungus described as non-pathogenic fungi and found in the human gastrointestinal tract as normal flora).

Glutaredoxin-4 has a vital role in the synthesis of iron-sulfur cofactor needed for many essential enzymes for DNA replication, mRNA translation, and biotin synthesis.[82-83]

Studying the glutaredoxin-4 enzyme is important because it is not found in humans and could be a good target for new antibacterial or antifungal drugs in the future.

\subsection{Glutaredoxin-5}

Glutaredoxin-5 protein is one of the important enzymes needed for iron hemostasis. Since glutaredoxin-5 is responsible for the biosynthesis of iron-sulfur clusters within the cell's mitochondria, any mutation of the glutaredoxin-5 (GLXR-5) gene could lead to iron overload in mitochondria or/and sideroblastic anemia*. GLXR-5 gene is found in chromosome 14 band q32.13 and highly encoded in skeletal muscle and white blood cells.

* Sideroblastic anemia: is defined as low hemoglobin level in red blood cells because of the inability of the mitochondria to metabolize or use the iron for producing new heme molecules.[84] 


\section{Role of Glutaredoxin-5 in iron metabolism (iron hemostasis):}

During red blood cells (RBCs) destruction inside macrophages cells found in liver spleen tissues, hemoglobin degraded into heme and globin protein. Globin protein is further destructed to form amino acids, used in anabolic reactions inside the human body. On the other hand, heme is further degraded to form biliverdin (converted to bilirubin by CYP1A2 enzyme to be excreted through bile duct) and iron (in the form of ferrous "Fe+2 "). Ferrous $(\mathrm{Fe}+2)$ formed by hemoglobin breakdown enters the mitochondria and bound to scaffold proteins called iron-sulfur cluster assembly enzyme (ISCU) by disulfide bonds. Then, glutaredoxin-5 (a monothiol glutaredoxin enzyme) breaches the disulfide bonds, thus forming iron-sulfur (Fe-S) clusters (see figure.10).[85]

Iron-sulfur clusters molecules are described as essential cofactors for many important enzymes, including enzymes responsible for:

1) citric acid cycle, which is responsible for the metabolism of carbohydrates, proteins, and fats, and convert them into adenosine triphosphate "ATP", a reduced form of nicotinamide adenine dinucleotide "NADH", a reduced form of flavin adenine dinucleotide "FADH2" and carbon dioxide "CO2". Aconitase enzyme is used in the Krebs cycle (citric acid cycle) to convert citrate to isocitrate, and this enzyme (aconitase) needs a Fe-S cluster as a cofactor (see figure.11).[86]

2) DNA repair, which needs AP (apurinic/apyrimidinic or also called abasic) endonuclease class III enzyme to remove the AP site (it is a nucleotide site in DNA, but no pyrimidine neither purine nucleotide present) in order to correct the damaged DNA.[87]

3) The synthesis of lipoyl. Iron-sulfur clusters are cofactors for the lipoyl synthase enzyme, which converts octanoyl molecules into lipoyl molecules. Since activating lipoyl synthase is responsible for the activation of pyruvate dehydrogenase enzyme (PDH), that converts pyruvate to acetyl-CoA. Therefore, lipoyl synthase with iron-sulfur clusters' aid is important for starting the Krebs cycle pathway.[88]

4) Biotin synthase (not found in humans), which is described as an important enzyme needed to synthesize vitamin B7 via the conversion of dethiobiotin into biotin. Biotin synthase enzyme needs an iron-sulfur cluster as a cofactor to produce its catalytic activity. Biotin synthase enzyme is encoded by the bioB gene found among Escherichia coli (E.coli) bacterial plasmid.[89]

\subsection{Effect of GLRX genes' polymorphisms on clopidogrel antiplatelet activity}

There is no well-study done about the relationship between GLRX genes' mutations and the clopidogrel platelet inhibition effect. However, a previous study showed that the GLRX enzyme has an important role in clopidogrel's activation process.[90] 


\section{Conclusion}

Some polymorphisms of G6PD, GCLC, GCLM, GSS, GST, GSR, HK, and GLRX genes could be responsible for clopidogrel resistance due to low glutathione conjugate or glutaredoxin plasma levels. However, few or no well-controlled studies were done about the relationship between the clopidogrel bioactivation process and genes related to phaseII metabolism's enzymes. Studies needed to be concerned with the relationship between clopidogrel resistance and phase-II metabolism issues in the near future. 
Conflicting interest: The authors have no relevant affiliations or financial involvement with any organization or entity with a financial interest in or financial conflict with the subject matter or materials discussed in the manuscript. This includes employment, consultancies, honoraria, stock ownership or options, expert testimony, grants or patents received or pending, or royalties.

Funding: This study was not funded.

Ethical approval: not applicable. 


\section{References}

1- Jung, Jung Hwa et al. "Current antiplatelet treatment strategy in patients with diabetes mellitus.” Diabetes \& metabolism journal vol. 39,2 (2015): 95-113. doi:10.4093/dmj.2015.39.2.95

2- Bernlochner I, Sibbing D. Thienopyridines and other ADP-receptor antagonists. Handb Exp Pharmacol. 2012,(210):165-98. doi: 10.1007/978-3-642-29423-5_7.

3- Frelinger AL 3rd, Bhatt DL et al. "Clopidogrel pharmacokinetics and pharmacodynamics vary widely despite exclusion or control of polymorphisms (CYP2C19, ABCB1, PON1), noncompliance, diet, smoking, co-medications (including proton pump inhibitors), and pre-existent variability in platelet function." Journal of the American College of Cardiology vol.61,8 (2013): 872879.

4- Zhu Y, Zhou J. In vitro biotransformation studies of 2-oxo-clopidogrel: multiple thiolactone ring-opening pathways further attenuate prodrug activation. Chem Res Toxicol. 2013 Jan 18,26(1):179-90. doi: 10.1021/tx300460k.

5- Hagihara K, Kazui M, Kurihara A, Ikeda T, Izumi T. Glutaredoxin is involved in the formation of the pharmacologically active metabolite of clopidogrel from its GSH conjugate. Drug Metab Dispos. 2012 Sep,40(9):1854-9. doi:

10.1124/dmd.112.045914.

6- Bubp, Jeff et al. "Caring for Glucose-6-Phosphate Dehydrogenase (G6PD)Deficient Patients: Implications for Pharmacy." P \& T : a peer-reviewed journal for formulary management vol. 40,9 (2015): 572-4.

7- Berkholz DS et al. "Catalytic cycle of human glutathione reductase near $1 \mathrm{~A}$ resolution". J Mol Biol. 2008 Oct 3,382(2):371-84.

8- Paramasivan K et al. "Regeneration of NADPH Coupled with HMG-CoA Reductase Activity Increases Squalene Synthesis in Saccharomyces cerevisiae". J Agric Food Chem. 2017 Sep 20,65(37):8162-8170.

9- Alharbi, Khalid K et al. "Insertion/Deletion polymorphisms do play any role in G6PD deficiency individuals in the Kingdom of the Saudi Arabia."

Bioinformation vol. 9,1 (2013): 49-53.

10- Gómez-Manzo, Saúl et al. “Glucose-6-Phosphate Dehydrogenase: Update and Analysis of New Mutations around the World." International journal of molecular sciences vol. 17,12 2069. 9 Dec. 2016.

11- McDonagh, Ellen M et al. "PharmGKB summary: very important pharmacogene information for G6PD." Pharmacogenetics and genomics vol. 22,3 (2012): 21928.

12- Kashmoola, Muna A et al. "Molecular Characterization of G6PD Deficient Variants in Nineveh Province, Northwestern Iraq." Indian journal of hematology \& blood transfusion : an official journal of Indian Society of Hematology and Blood Transfusion vol. 31,1 (2015): 133-6.

13- Sirdah M et al. "Hemolysis and Mediterranean G6PD mutation (c.563 C > T) and c.1311 C>T polymorphism among Palestinians at Gaza Strip”. Blood Cells Mol Dis. 2012 Apr 15,48(4):203-8. 
14- Alfadhli S et al. "Molecular characterization of glucose-6-phosphate dehydrogenase gene defect in the Kuwaiti population". Arch Pathol Lab Med. 2005 Sep, 129(9):1144-7.

15- Manjurano, Alphaxard et al. "African glucose-6-phosphate dehydrogenase alleles associated with protection from severe malaria in heterozygous females in Tanzania." PLoS genetics vol. 11,2 e1004960. 11 Feb. 2015.

16- Dern RJ et al. "A new structural variant of glucose-6-phosphate dehydrogenase with a high production rate (G6PD Hektoen)". J Lab Clin Med. 1969 Feb,73(2):283-90.

17-Zhang, Haoming et al. "Formation, reactivity, and antiplatelet activity of mixed disulfide conjugates of clopidogrel." Molecular pharmacology vol. 83,4 (2013): 848-56.

18- Espinosa-Diez, Cristina et al. "Targeting of Gamma-Glutamyl-Cysteine Ligase by miR-433 Reduces Glutathione Biosynthesis and Promotes TGF- $\beta$-Dependent Fibrogenesis.” Antioxidants \& redox signaling vol. 23,14 (2015): 1092-105.

19- Franklin, Christopher C et al. "Structure, function, and post-translational regulation of the catalytic and modifier subunits of glutamate cysteine ligase." Molecular aspects of medicine vol. 30,1-2 (2009): 86-98.

20- Wang, Danxin et al. "Polymorphism in glutamate cysteine ligase catalytic subunit (GCLC) is associated with sulfamethoxazole-induced hypersensitivity in HIV/AIDS patients.” BMC medical genomics vol. 5 32. 23 Jul. 2012.

21- Campolo J et al. "Glutamate-cysteine ligase polymorphism, hypertension, and male sex are associated with cardiovascular events. Biochemical and genetic characterization of Italian subpopulation”. Am Heart J. 2007 Dec,154(6):1123-9. Epub 2007 Sep 6.

22- Lu, Shelly C. "Glutathione synthesis.” Biochimica et biophysica acta vol. 1830,5 (2013): 3143-53.

23-Xia, H et al. "A case of severe glutathione synthetase deficiency with novel GSS mutations." Brazilian journal of medical and biological research $=$ Revista brasileira de pesquisas medicas e biologicas vol. 51,3 e6853. 11 Jan. 2018.

24-Shi, Z., Habib, G., Rhead, W. et al. Mutations in the glutathione synthetase gene cause 5-oxoprolinuria. Nat Genet 14, 361-365 (1996).

25- Njålsson, R., Ristoff, E., Carlsson, K. et al. Genotype, enzyme activity, glutathione level, and clinical phenotype in patients with glutathione synthetase deficiency. Hum Genet 116, 384-389 (2005).

26- Li X et al. "Five Chinese patients with 5-oxoprolinuria due to glutathione synthetase and 5-oxoprolinase deficiencies". Brain Dev. 2015 Nov,37(10):952-9.

27- Soylu Ustkoyuncu P et al. "A Rare Cause of Neonatal Hemolytic Anemia: Glutathione Synthetase Deficiency”. J Pediatr Hematol Oncol. 2018 Jan,40(1):e45-e49.

28- Dong, Shu-Chen et al. "Glutathione S-transferase $\pi$ : a potential role in antitumor therapy." Drug design, development and therapy vol. 12 3535-3547. 23 Oct. 2018. 
29- Pearson, W R et al. "Identification of class-mu glutathione transferase genes GSTM1-GSTM5 on human chromosome 1p13." American journal of human genetics vol. 53,1 (1993): 220-33.

30- Hadami, Khaoula et al. "Evaluation of glutathione S-transferase pi 1 expression and gene promoter methylation in Moroccan patients with urothelial bladder cancer." Molecular genetics \& genomic medicine vol. 6,5 (2018): 819-827.

31- Hansen, Keith A, and Kathleen M Eyster. "Genetics and genomics of endometriosis." Clinical obstetrics and gynecology vol. 53,2 (2010): 403-12.

32- Matsumura T et al. "Human glutathione S-transferase A (GSTA) family genes are regulated by steroidogenic factor 1 (SF-1) and are involved in steroidogenesis". FASEB J. 2013 Aug,27(8):3198-208.

33- Nebert, Daniel W, and Vasilis Vasiliou. "Analysis of the glutathione S-transferase (GST) gene family." Human genomics vol. 1,6 (2004): 460-4.

34- Adams CH et al. "Allele frequencies for glutathione S-transferase and $\mathrm{N}$ acetyltransferase 2 differ in African population groups and may be associated with oesophageal cancer or tuberculosis incidence". Clin Chem Lab Med. 2003 Apr,41(4):600-5.

35- Roodi $\mathrm{N}$ et al. "Association of homozygous wild-type glutathione S-transferase M1 genotype with increased breast cancer risk". Cancer Res. 2004 Feb 15,64(4):1233-6.

36- Sharma, Anita et al. "Genetic polymorphism of glutathione S-transferase P1 (GSTP1) in Delhi population and comparison with other global populations." Meta gene vol. 2 134-42. 20 Jan. 2014.

37- Cho, Hyun-Jung et al. "GSTM1, GSTT1 and GSTP1 polymorphisms in the Korean population.” Journal of Korean medical science vol. 20,6 (2005): 108992.

38- Bremer, Sara et al. "Glutathione Transferase Gene Variants Influence Busulfan Pharmacokinetics and Outcome After Myeloablative Conditioning." Therapeutic drug monitoring vol. 37,4 (2015): 493-500.

39- Sharif, Mohammad Reza et al. "Association of GSTO1 A140D and GSTO2 N142D Gene Variations with Breast Cancer Risk." Asian Pacific journal of cancer prevention : APJCP vol. 18,6 1723-1727. 25 Jun. 2017.

40- White CW et al. "Accumulation of lung tissue oxidized glutathione (GSSG) as a marker of oxidant induced lung injury". Chest. 1986 Mar,89(3 Suppl):111S-113S.

41- Pekkanen $\mathrm{L}$ et al. "The effects of dietary niacin and riboflavin on voluntary intake and metabolism of ethanol in rats". Pharmacol Biochem Behav. 1979 Nov, 11(5):575-9.

42- Baity, Mohamed et al. "Glutathione reductase (GSR) gene deletion and chromosome 8 aneuploidy in primary lung cancers detected by fluorescence in situ hybridization." American journal of cancer research vol. 9,6 1201-1211. 1 Jun. 2019. 
43- Kitoh R et al. "Prognostic impact of gene polymorphisms in patients with idiopathic sudden sensorineural hearing loss". Acta Otolaryngol. 2017,137(sup565):S24-S29.

44- Sharma, Vandana et al. "Mannose metabolism: more than meets the eye." Biochemical and biophysical research communications vol. 453,2 (2014): 220-8.

45- Medrano A et al. "Hexose-specificity of hexokinase and ADP-dependence of pyruvate kinase play important roles in the control of monosaccharide utilization in freshly diluted boar spermatozoa". Mol Reprod Dev. 2006 Sep,73(9):1179-94.

46- Zhang, Zhaoyun et al. "Increasing glucose 6-phosphate dehydrogenase activity restores redox balance in vascular endothelial cells exposed to high glucose." PloS one vol. 7,11 (2012): e49128.

47- Harrington, Gregory N, and Daniel R Bush. "The bifunctional role of hexokinase in metabolism and glucose signaling." The Plant cell vol. 15,11 (2003): 2493-6.

48- Sullivan LS et al. "A dominant mutation in hexokinase 1 (HK1) causes retinitis pigmentosa". Invest Ophthalmol Vis Sci. 2014 Sep 4,55(11):7147-58.

49- Suazo, José et al. "Family-based association study between SLC2A1, HK1, and LEPR polymorphisms with myelomeningocele in Chile." Reproductive sciences (Thousand Oaks, Calif.) vol. 20,10 (2013): 1207-14.

50- Sevilla T et al. "Genetics of the Charcot-Marie-Tooth disease in the Spanish Gypsy population: the hereditary motor and sensory neuropathy-Russe in depth". Clin Genet. 2013 Jun, 83(6):565-70.

51- Gabrikova D et al. "Founder mutations in NDRG1 and HK1 genes are common causes of inherited neuropathies among Roma/Gypsies in Slovakia”. J Appl Genet. 2013 Nov,54(4):455-60.

52- Hui Liu et al. "The contribution of hexokinase 2 in glioma". Cancer translational medicine Year:2018 Volume:4 Issue:2 Page:54-58.

53- M. Lehto et al. "Human hexokinase II gene: exon-intron organization, mutation screening in NIDDM, and its relationship to muscle hexokinase activity”. Diabetologia. 1995 Dec,38(12):1466-74.

54- Echwald SM et al. "Identification of four amino acid substitutions in hexokinase II and studies of relationships to NIDDM, glucose effectiveness, and insulin sensitivity". Diabetes. 1995 Mar,44(3):347-53.

55- Ardehali H et al. "A novel (TA)n polymorphism in the hexokinase II gene: application to noninsulin-dependent diabetes mellitus in the Pima Indians". Hum Genet. 1996 Apr,97(4):482-5.

56- Roberts, D J, and S Miyamoto. "Hexokinase II integrates energy metabolism and cellular protection: Akting on mitochondria and TORCing to autophagy." Cell death and differentiation vol. 22,2 (2015): 248-57.

57- Rabbani N et al. "Hexokinase-2 Glycolytic Overload in Diabetes and IschemiaReperfusion Injury”. Trends Endocrinol Metab. 2019 Jul,30(7):419-431. 
58- Colosimo A et al. "Assignment of the hexokinase type 3 gene (HK3) to human chromosome band $5 q 35.3$ by somatic cell hybrids and in situ hybridization". Cytogenet Cell Genet. 1996,74(3):187-8.

59- Qin, Yingying et al. "ESR1, HK3 and BRSK1 gene variants are associated with both age at natural menopause and premature ovarian failure." Orphanet journal of rare diseases vol. 7 5. 17 Jan. 2012.

60- Nishi S et al. "Human pancreatic beta-cell glucokinase: cDNA sequence and localization of the polymorphic gene to chromosome 7, band p 13". Diabetologia. 1992 Aug,35(8):743-7.

61- Matschinsky, Franz M, and David F Wilson. "The Central Role of Glucokinase in Glucose Homeostasis: A Perspective 50 Years After Demonstrating the Presence of the Enzyme in Islets of Langerhans." Frontiers in physiology vol. 10 148. 6 Mar. 2019.

62- Wędrychowicz, Anna et al. "Phenotype Heterogeneity in Glucokinase-MaturityOnset Diabetes of the Young (GCK-MODY) Patients." Journal of clinical research in pediatric endocrinology vol. 9,3 (2017): 246-252.

63- Tinto, Nadia et al. "Glucokinase gene mutations: structural and genotypephenotype analyses in MODY children from South Italy." PloS one vol. 3,4 e1870. 2 Apr. 2008.

64- Bonfig W et al. "GCK-MODY (MODY 2) Caused by a Novel p.Phe330Ser Mutation”. ISRN Pediatr. 2011,2011:676549.

65- Lukásová P et al. "Screening of mutations and polymorphisms in the glucokinase gene in Czech diabetic and healthy control populations". Physiol Res. 2008,57 Suppl 1:S99-108. Epub 2008 Feb 13.

66- Beer NL et al. "Insights into the pathogenicity of rare missense GCK variants from the identification and functional characterization of compound heterozygous and double mutations inherited in cis". Diabetes Care. 2012 Jul,35(7):1482-4.

67- Osbak KK et al. "Update on mutations in glucokinase (GCK), which cause maturity-onset diabetes of the young, permanent neonatal diabetes, and hyperinsulinemic hypoglycemia”. Hum Mutat. 2009 Nov,30(11):1512-26.

68- Khalil R et al. "Screening of mutations in the GCK gene in Jordanian maturityonset diabetes of the young type 2 (MODY2) patients". Genet Mol Res. 2009 May 5,8(2):500-6.

69- Sabah M. Hassan et al. "Screening for Glucokinase (GCK) Gene Mutation in Gestational Diabetes Women in Western Region of Saudi Arabia”. British Journal of Medicine \& Medical Research 13(8): 1-10, 2016.

70- 252- Su J et al. "Association of GCK gene DNA methylation with the risk of clopidogrel resistance in acute coronary syndrome patients.” J Clin Lab Anal. 2020 Feb,34(2):e23040.

71- Gallogly, Molly M et al. "Mechanistic and kinetic details of catalysis of thioldisulfide exchange by glutaredoxins and potential mechanisms of regulation." Antioxidants \& redox signaling vol. 11,5 (2009): 1059-81. 
72- Rodríguez-Manzaneque, María Teresa et al. "Grx5 is a mitochondrial glutaredoxin required for the activity of iron/sulfur enzymes." Molecular biology of the cell vol. 13,4 (2002): 1109-21.

73- Hoffmann B et al. "The multidomain thioredoxin-monothiol glutaredoxins represent a distinct functional group”. Antioxid Redox Signal. 2011 Jul 1,15(1):19-30.

74- Park JB et al. "Cloning, sequencing, and characterization of alternatively spliced glutaredoxin 1 cDNA and its genomic gene: chromosomal localization, mrna stability, and origin of pseudogenes”. J Biol Chem. 2005 Mar 18,280(11):1042734. Epub 2005 Jan 6.

75- Gladyshev VN et al. "Identification and characterization of a new mammalian glutaredoxin (thioltransferase), Grx2”. J Biol Chem. 2001 Aug 10,276(32):3037480. Epub 2001 Jun 7.

76- Wu, HongLi et al. "Glutaredoxin 2 knockout increases sensitivity to oxidative stress in mouse lens epithelial cells." Free radical biology \& medicine vol. 51,11 (2011): 2108-17.

77- Lillig $\mathrm{CH}$ et al. "Characterization of human glutaredoxin 2 as iron-sulfur protein: a possible role as redox sensor". Proc Natl Acad Sci U S A. 2005 Jun 7,102(23):8168-73. Epub 2005 May 25.

78- Johansson $\mathrm{C}$ et al. "Human mitochondrial glutaredoxin reduces S-glutathionylated proteins with high affinity accepting electrons from either glutathione or thioredoxin reductase". J Biol Chem. 2004 Feb 27,279(9):7537-43. Epub 2003 Dec 4.

79- Čiuladaitė $\check{Z}$ et al. "Clinical, cytogenetic and molecular study of a case of ring chromosome 10". Mol Cytogenet. 2015 Apr 21,8:29.

80- Haunhorst P et al. "Characterization of the human monothiol glutaredoxin 3 (PICOT) as iron-sulfur protein”. Biochem Biophys Res Commun. 2010 Apr 2,394(2):372-6.

81- Frey AG et al. "A Glutaredoxin·BolA Complex Serves as an Iron-Sulfur Cluster Chaperone for the Cytosolic Cluster Assembly Machinery”. J Biol Chem. 2016 Oct 21,291(43):22344-22356.

82- Fernandes AP et al. "A novel monothiol glutaredoxin (Grx4) from Escherichia coli can serve as a substrate for thioredoxin reductase". J Biol Chem. 2005 Jul 1,280(26):24544-52. Epub 2005 Apr 15.

83- Ojeda L et al. "Role of glutaredoxin-3 and glutaredoxin-4 in the iron regulation of the Aft1 transcriptional activator in Saccharomyces cerevisiae”. J Biol Chem. 2006 Jun 30,281(26):17661-9. Epub 2006 Apr 28.

84- Ye, Hong et al. "Glutaredoxin 5 deficiency causes sideroblastic anemia by specifically impairing heme biosynthesis and depleting cytosolic iron in human erythroblasts." The Journal of clinical investigation vol. 120,5 (2010): 1749-61.

85- Wingert RA et al. "Deficiency of glutaredoxin 5 reveals Fe-S clusters are required for vertebrate haem synthesis". Nature. 2005 Aug 18,436(7053):1035-39. 
86- Tong WH et al. "Metabolic regulation of citrate and iron by aconitases: role of iron-sulfur cluster biogenesis”. Biometals. 2007 Jun,20(3-4):549-64. Epub 2007 Jan 5.

87- Fuss, Jill $\mathrm{O}$ et al. "Emerging critical roles of Fe-S clusters in DNA replication and repair.” Biochimica et biophysica acta vol. 1853,6 (2015): 1253-71.

88- McCarthy, Erin L, and Squire J Booker. "Destruction and reformation of an ironsulfur cluster during catalysis by lipoyl synthase." Science (New York, N.Y.) vol. 358,6361 (2017): 373-377.

89- Ugulava NB et al. "Biotin synthase contains two distinct iron-sulfur cluster binding sites: chemical and spectroelectrochemical analysis of iron-sulfur cluster interconversions". Biochemistry. 2001 Jul 27,40(28):8343-51.

90- Hagihara K, Kazui M, Kurihara A, et al. Glutaredoxin is involved in the formation of the pharmacologically active metabolite of clopidogrel from its GSH conjugate. Drug Metab Dispos. 2012 Sep;40(9):1854-1859. 


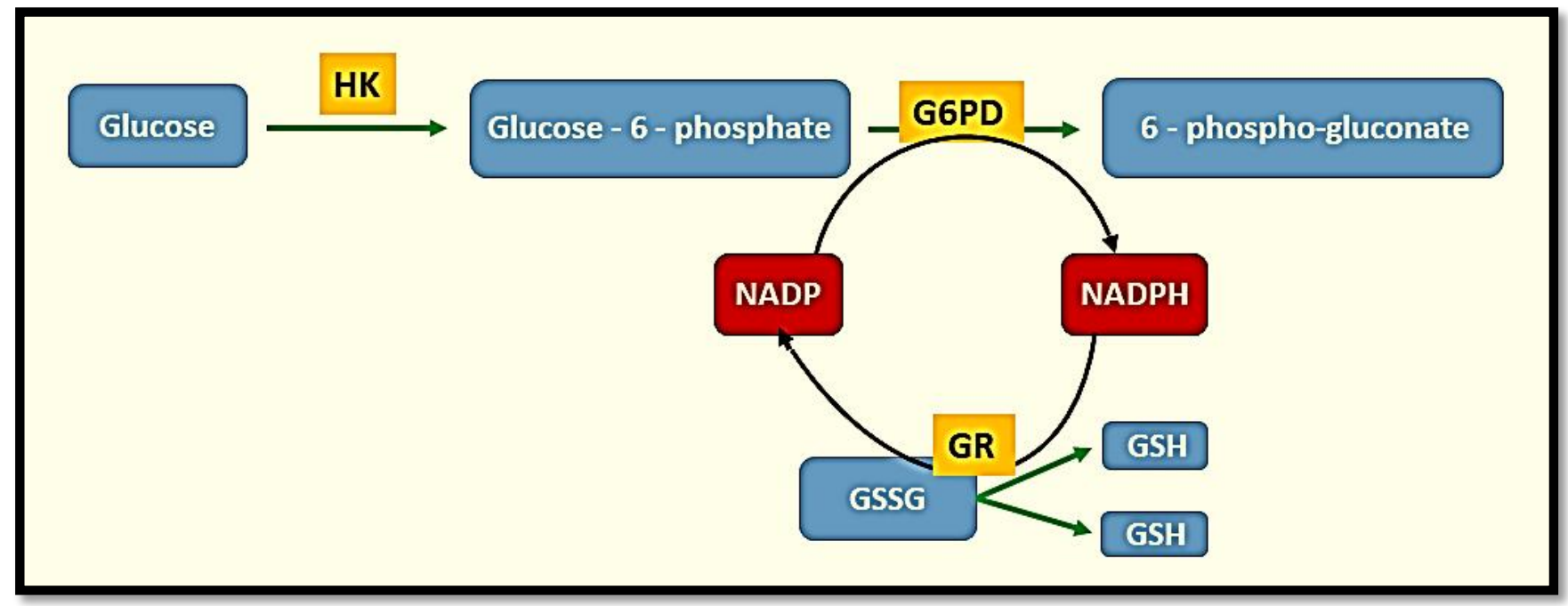

Figure.1 Role of HK (hexokinase), G6PD (glucose-6-phosphate dehydrogenase) and GR (glutathione reductase) Enzymes in Synthesis of 2 GSH.

${ }^{*}$ GSSG: oxidized glutathione.

${ }^{*} \mathrm{GSH}$ : free glutathione.

*NADP: nicotinamide adenine dinucleotide phosphate.

*NADPH: reduced form of nicotinamide adenine dinucleotide phosphate. 


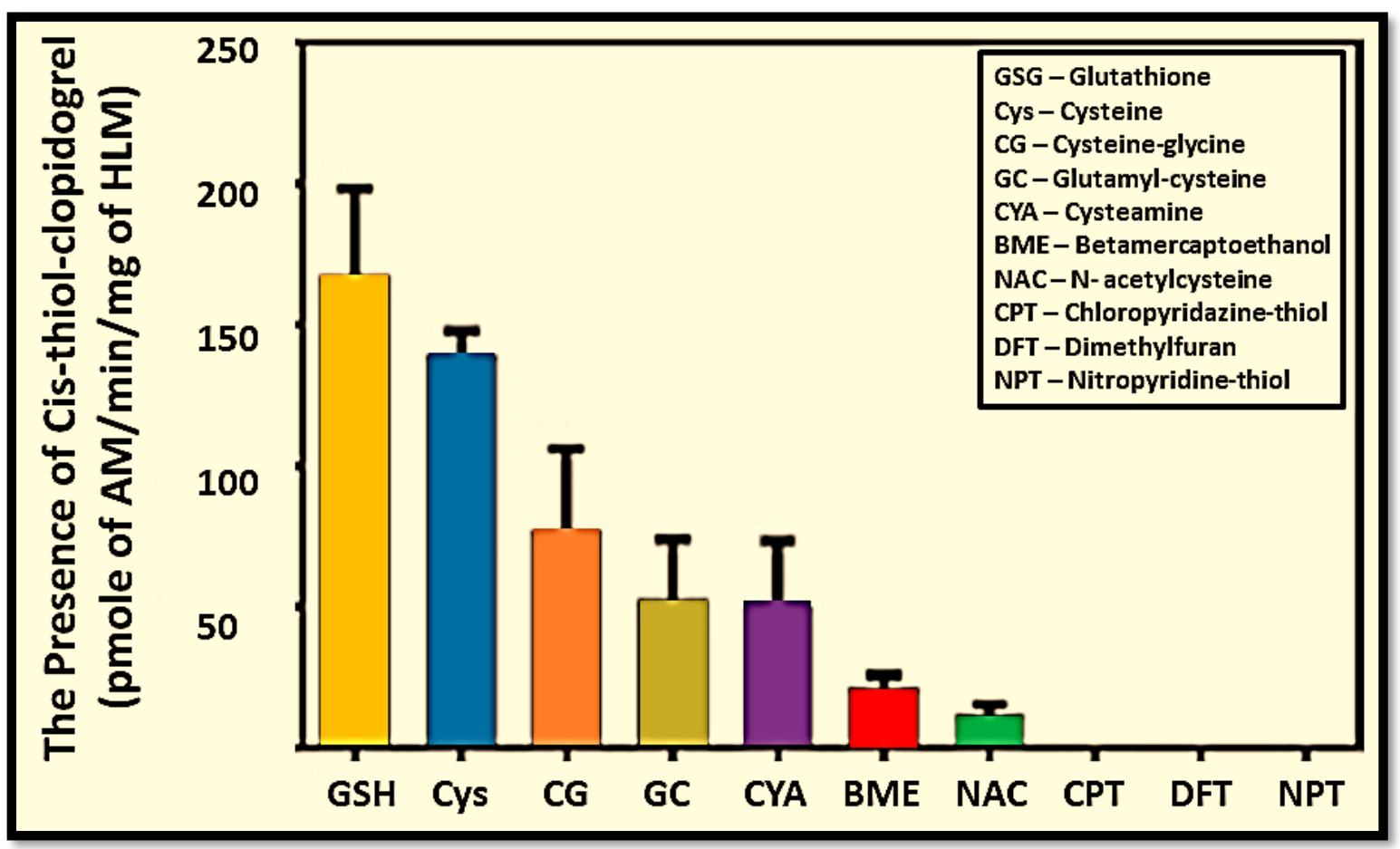

Figure.2 The Effect of Different Thiol Reductants on Converting Inactive Clopidogrel into The Active Metabolite Inside the Human Liver Microsomes (HLM).

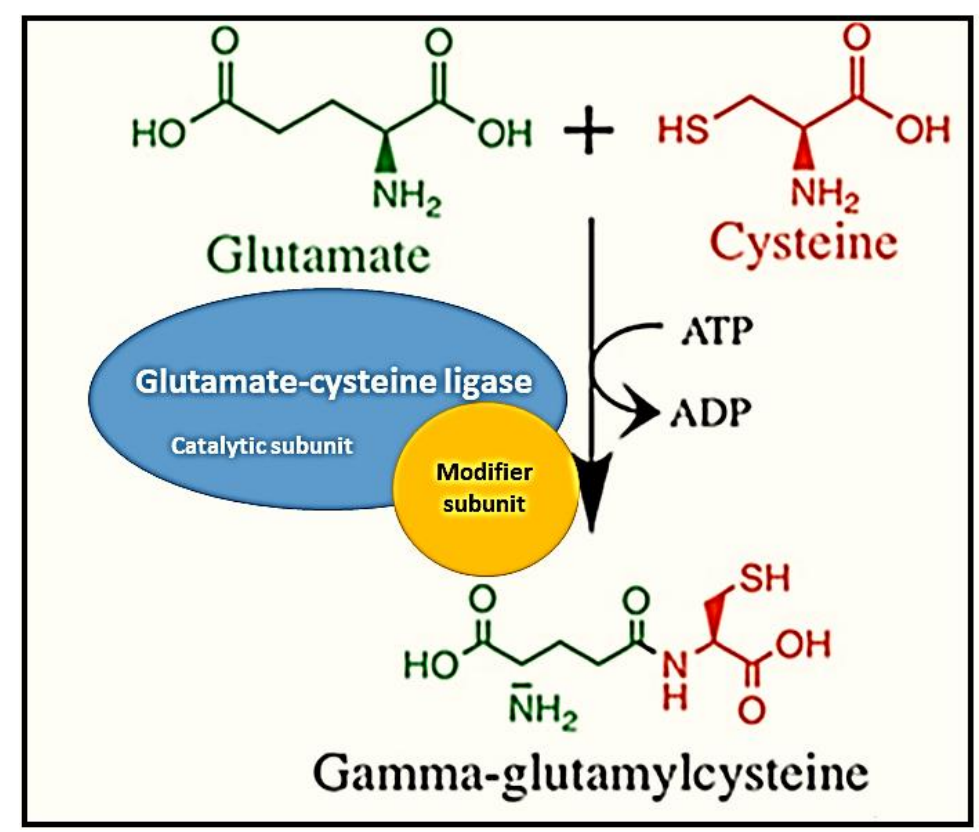

Figure. 3 The Role of Glutamate-cysteine ligase catalytic and modifier subunits (GCLC and GCLM) in The Biosynthesis of Glutathione (GSH).

*ATP: adenosine triphosphate. 
*ADP: adenosine diphosphate.

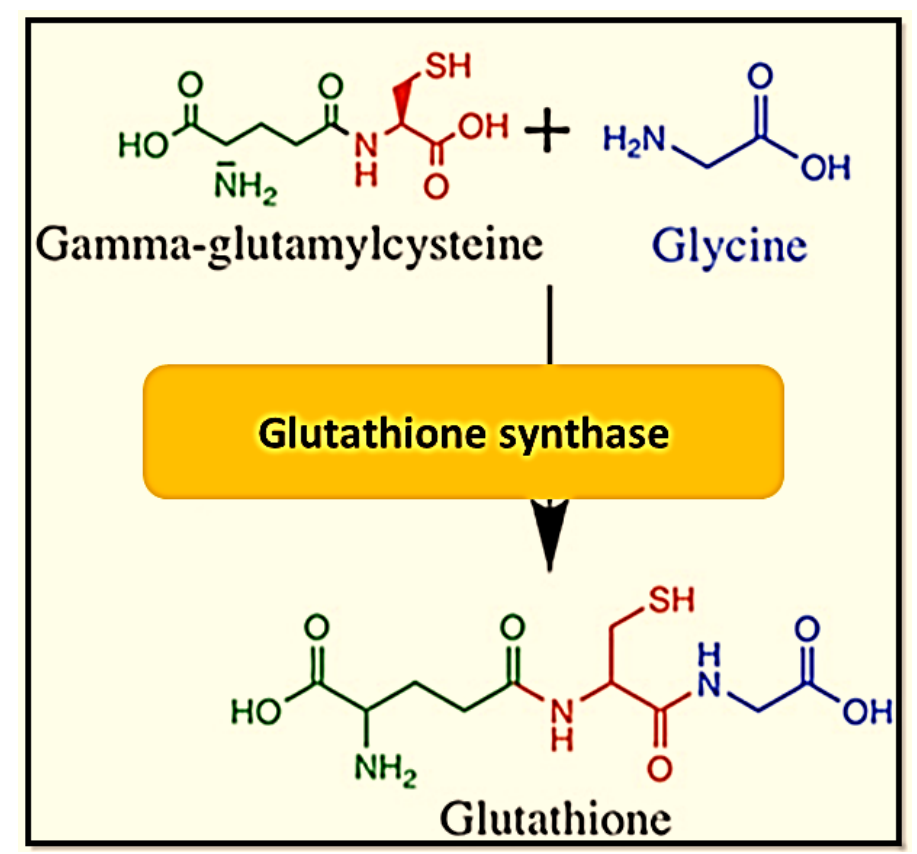

Figure.4 The Role of Glutathione Synthase (GSS) Enzyme in The Biosynthesis of Glutathione (GSH). 


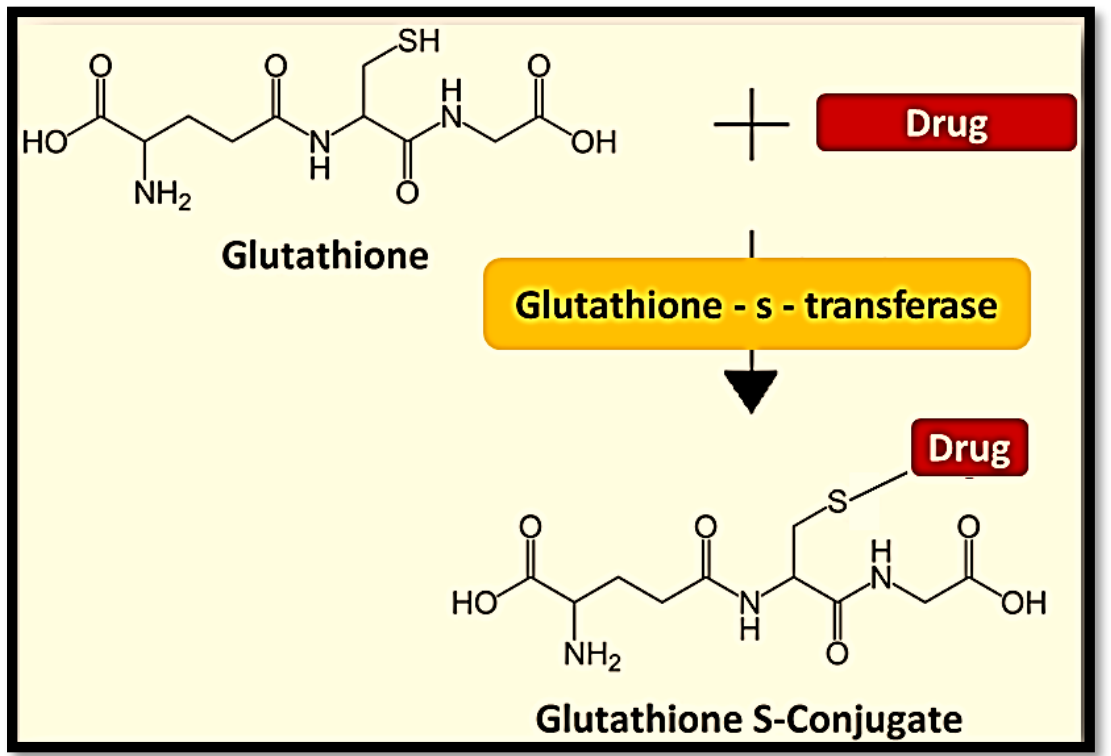

Figure.5 Role

Glutathione-S-transferase (GST) in the conjugation process.

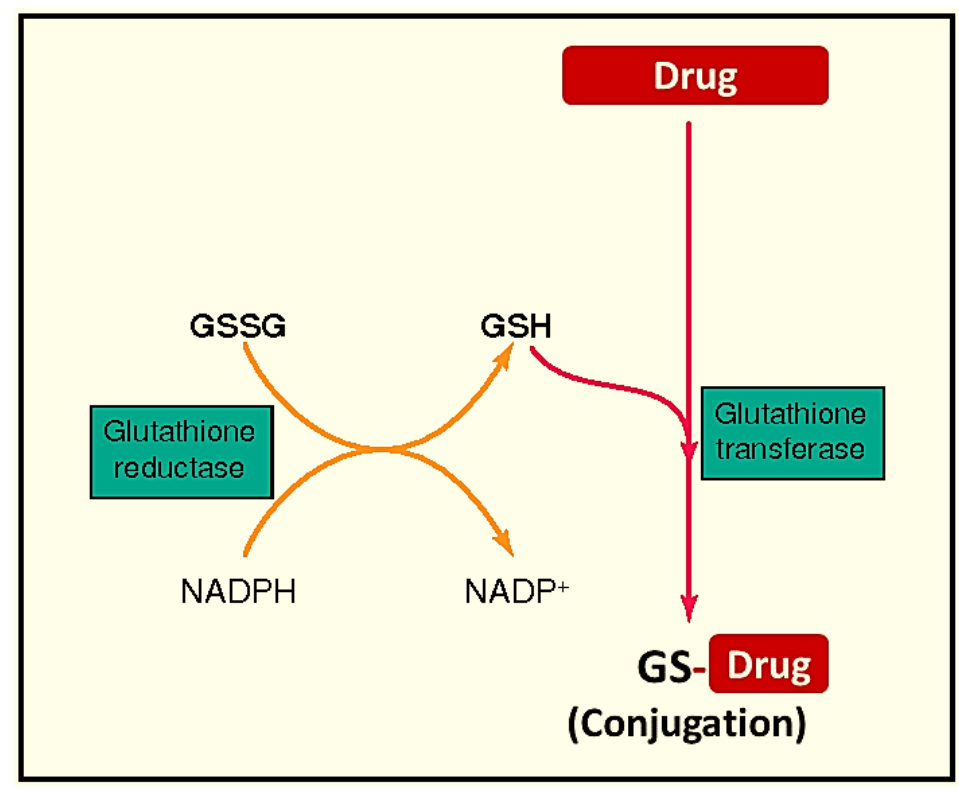

Figure.6 Role of Glutathione reductase (GR) Enzyme in The Metabolism of Drugs. 


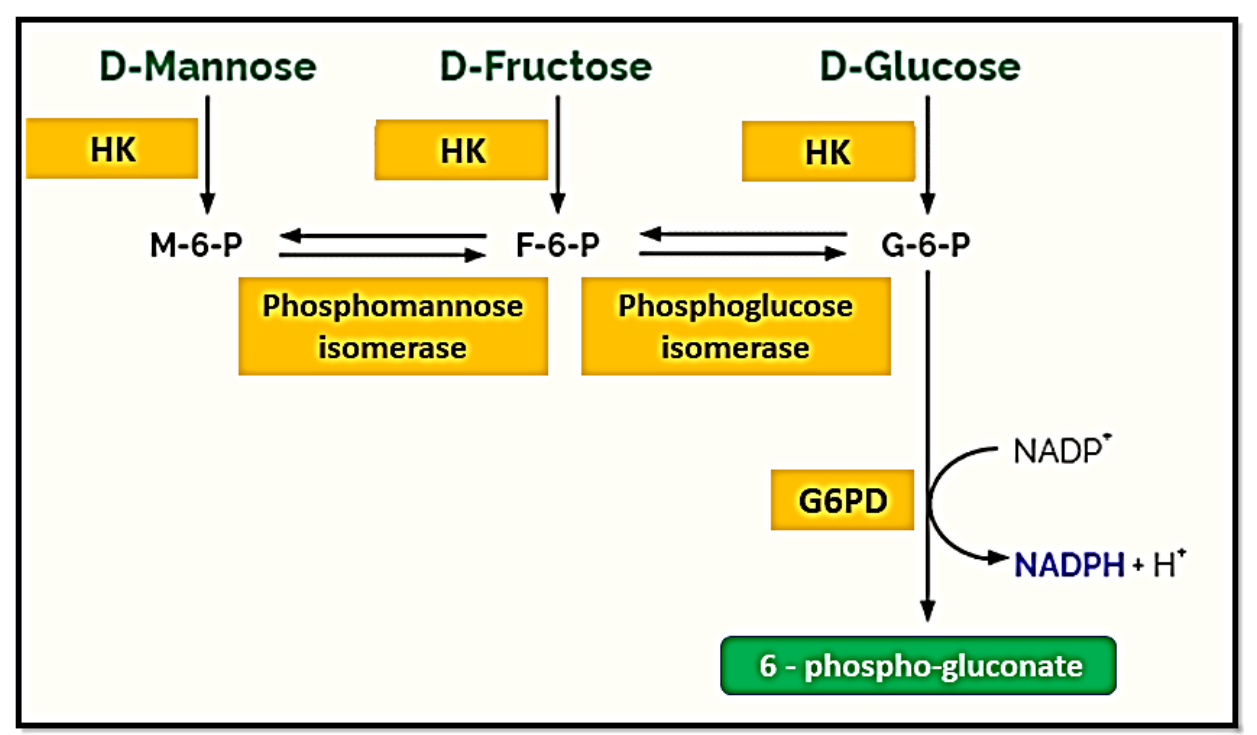

Figure.7 Role of Hexokinase (HK) Enzyme in the Metabolism of Some Monosaccharides.

*M-6-P: mannose-6-phosphate.

*F-6-P: fructose-6-phosphate.

*G-6-P: glucose-6-phosphate. 


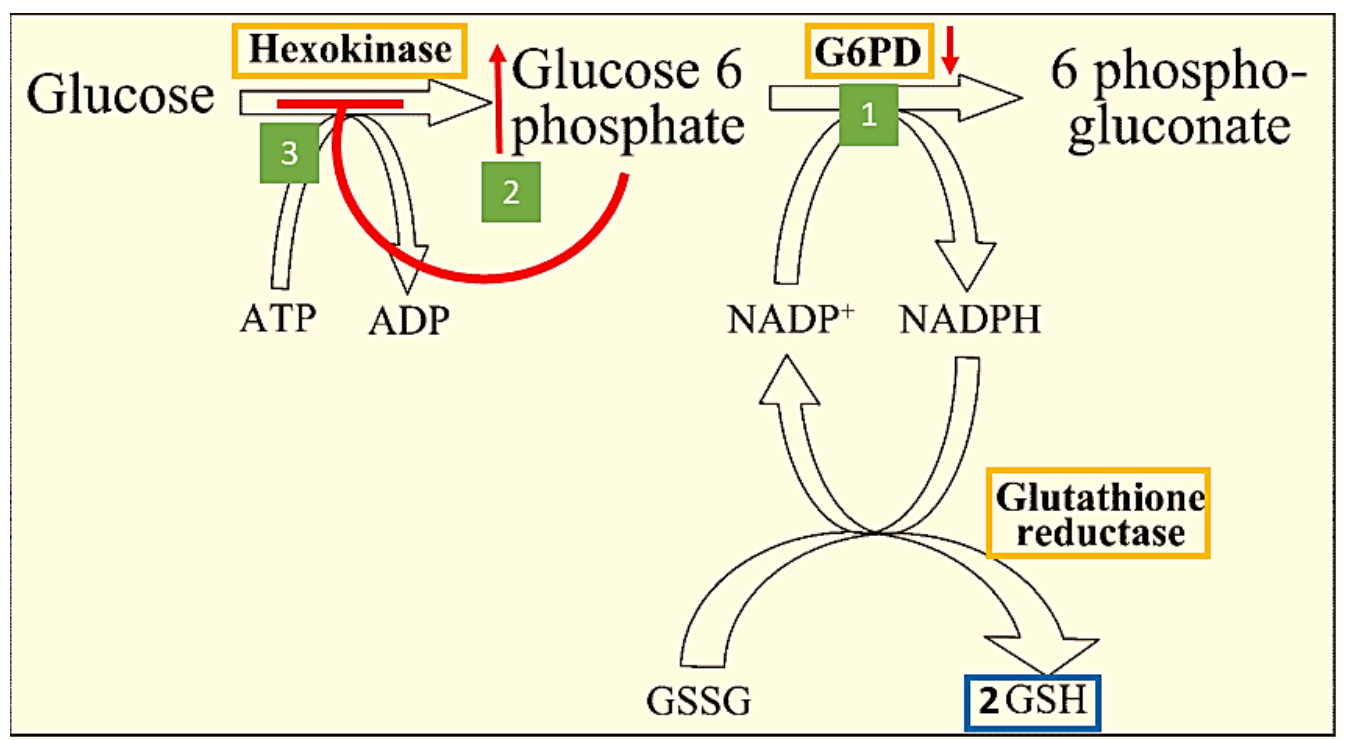

Figure.8 The Effect of Glucose-6-phosphate and Glucose-6-phosphate dehydrogenase Levels Alteration on Hexokinase Activity.

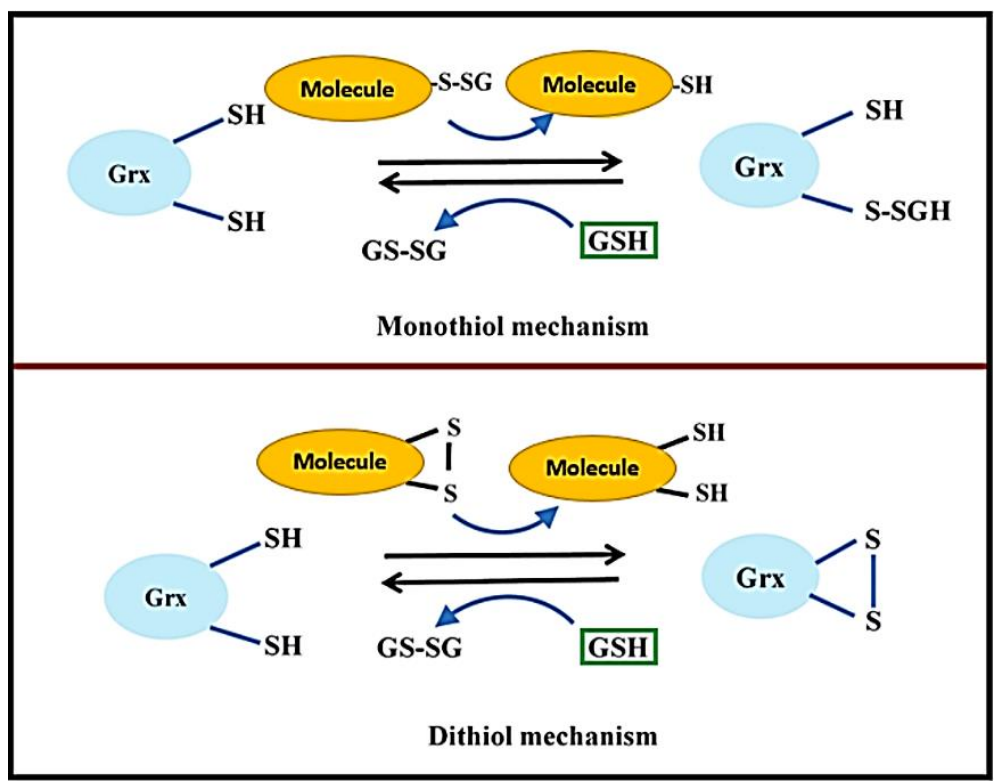

Figure.9 The Two Mechanisms of Glutaredoxin (Grx) Enzyme in Breaking Disulfide Bond of Different Molecules. 


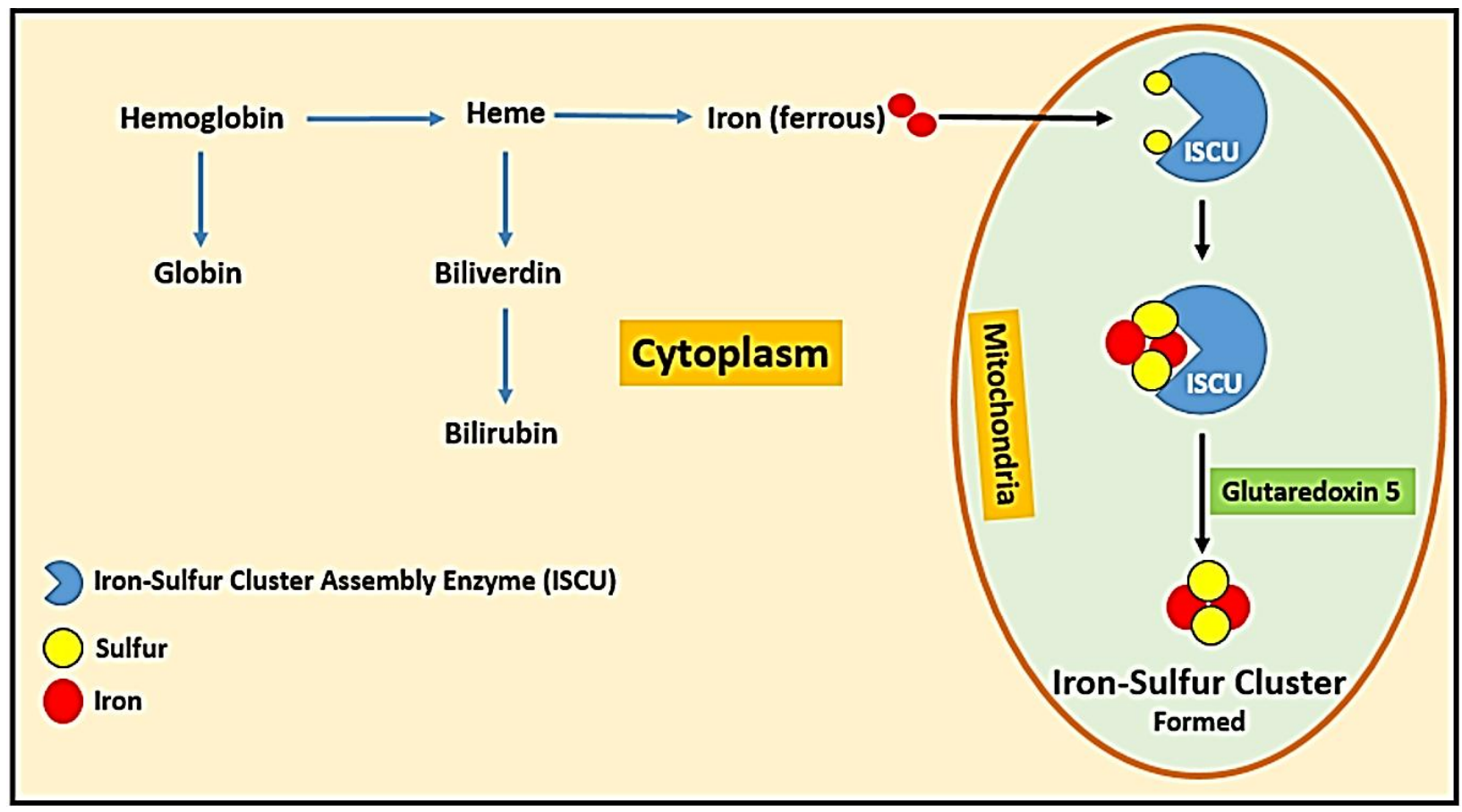

Figure.10 The Role of Glutaredoxin-5 in The Formation of Iron-Sulfur Clusters. 


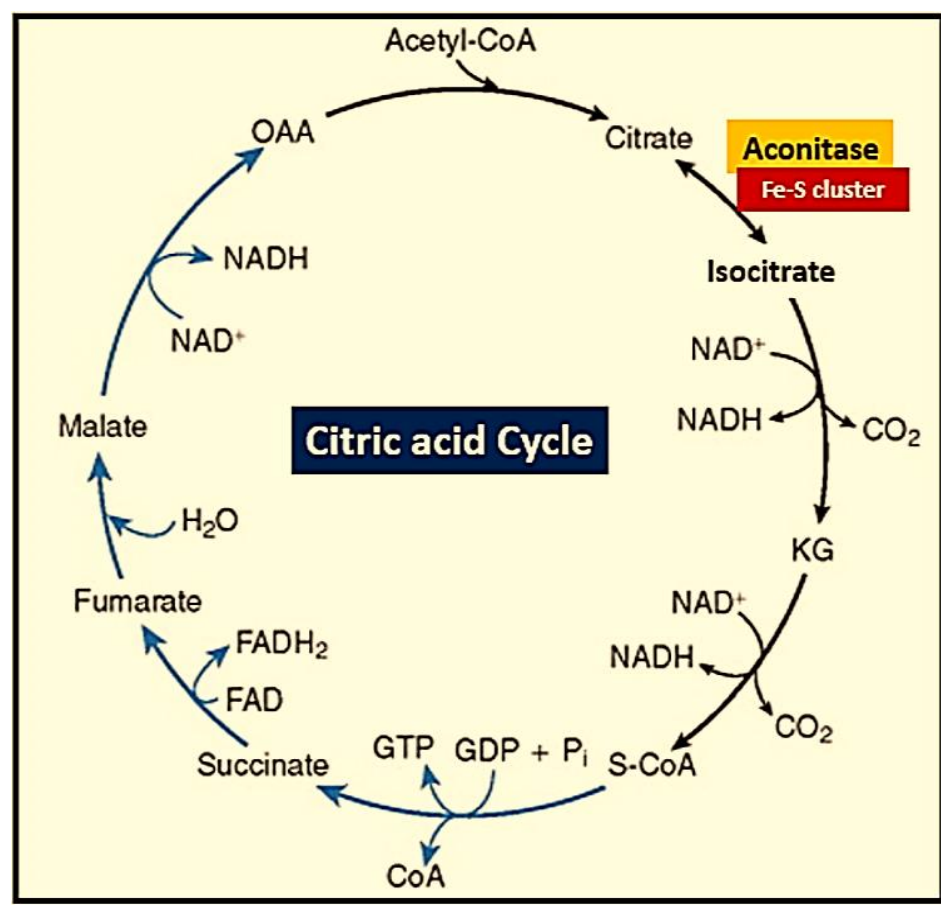

Figure.11 Role of Iron-Sulfur Clusters as A Cofactor for Aconitase Enzyme in The Citric Acid Cycle. 
Table.1 Polymorphisms of G6PD gene and their phenotypes.

\begin{tabular}{|c|c|}
\hline G6PD Allele & G6PD Enzyme Activity \\
\hline G6PD A+ & $>60 \%$ \\
\hline G6PD B & $>60 \%$ \\
\hline G6PD A- & $10-60 \%$ \\
\hline G6PD Canton & $10-60 \%$ \\
\hline G6PD Aures & $10-60 \%$ \\
\hline G6PD Mediterranean & $<10 \%$ \\
\hline G6PD Chatham & $<10 \%$ \\
\hline G6PD Hektoen & Up to $400 \%$ \\
\hline
\end{tabular}


Table.2 Most Common Types of Glutathione-S-transferase (GST) Genes and Their Characteristics.

\begin{tabular}{|c|c|c|c|c|}
\hline Type of Hexokinase & Hexokinase-1 & Hexokinase-2 & Hexokinase-3 & Hexokinase-4 \\
(Glucokinase)
\end{tabular}


Table.3 Summary about Different Types of hexokinase (HK) Enzymes.

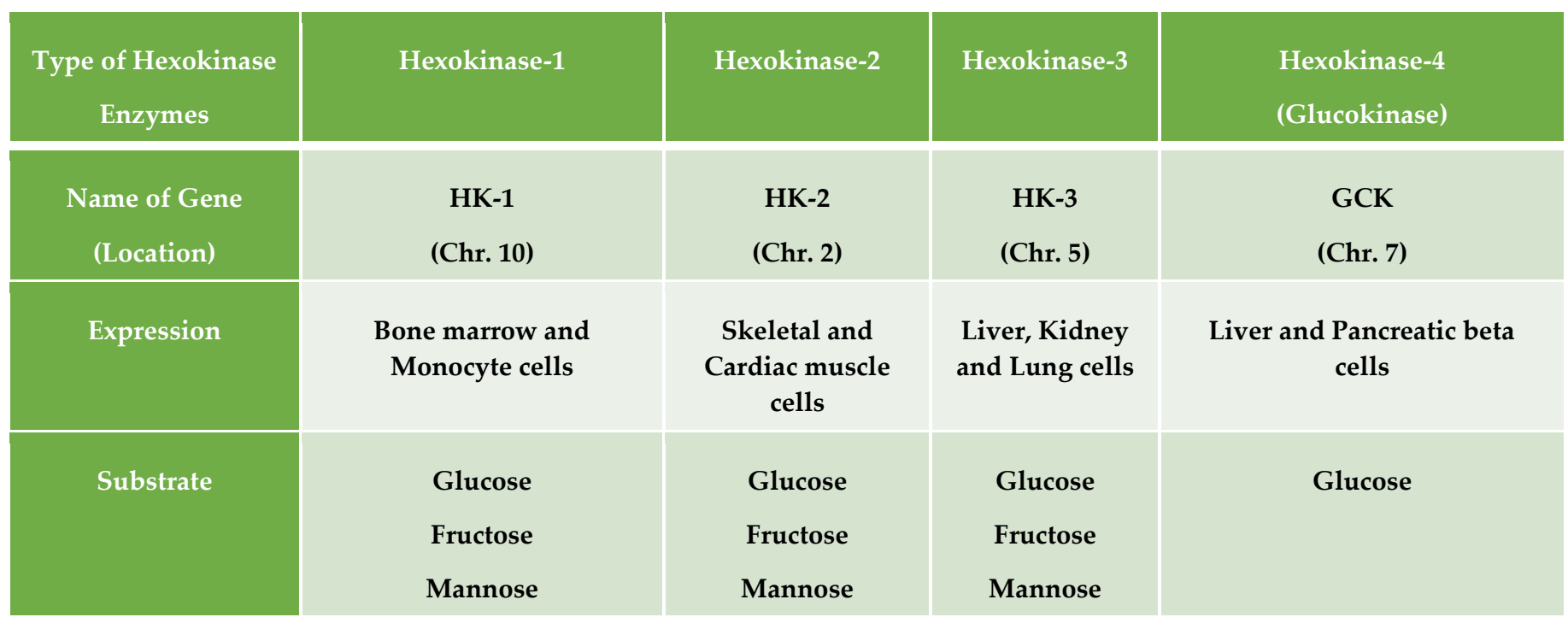


Table.4 Summary about Different Types of Glutaredexin (GLRX) Enzymes.

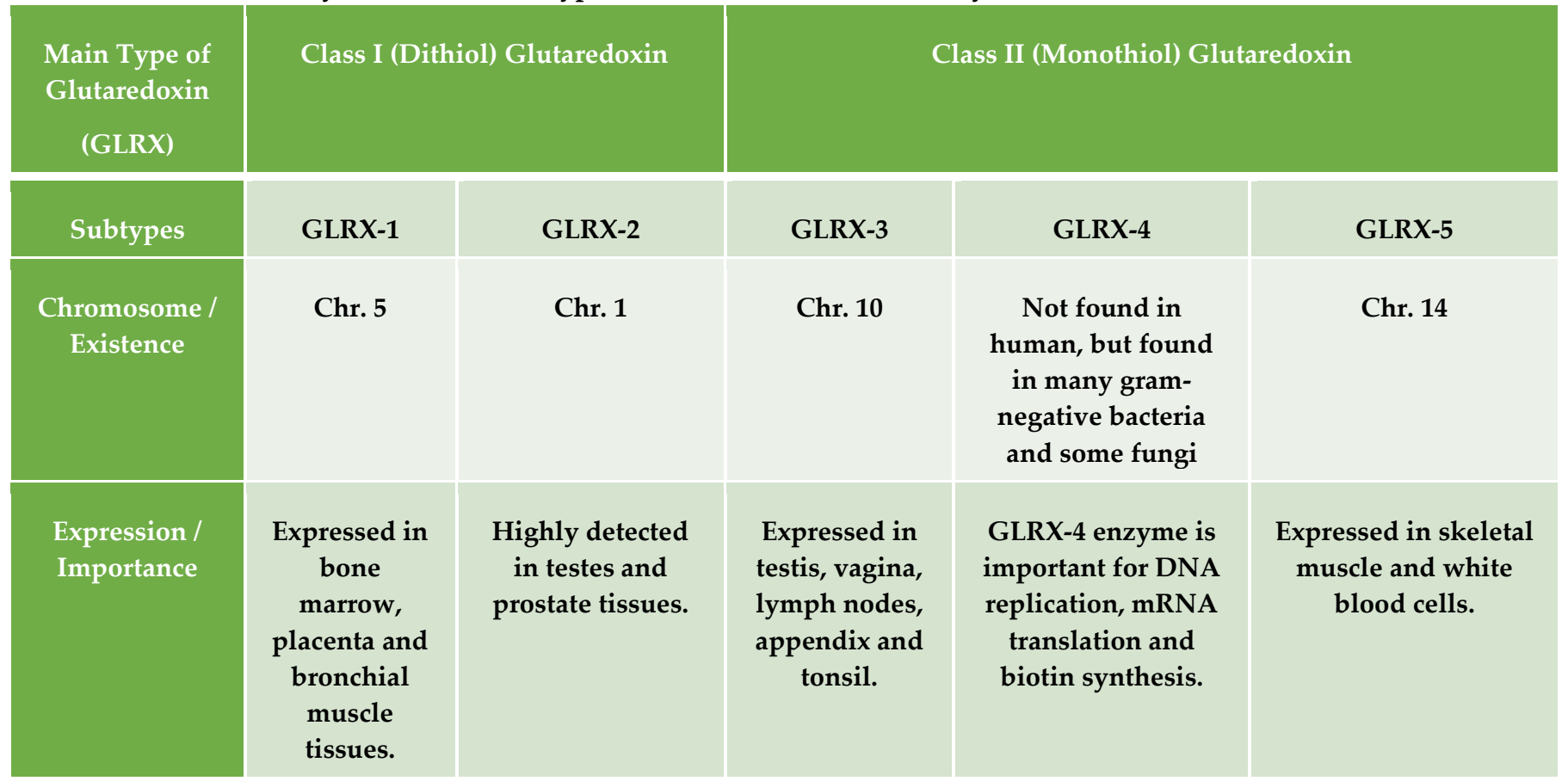

